\title{
Örtüaltı domates yetiştiriciliğinde değişen sıcaklık ve ışık koşulları ile verim parametreleri arasındaki ilişkinin modellenmesi
}

\section{Modelling the relationship on changing temperature and light conditions and yield in greenhouse tomato cultivation}

\author{
Melek ÖZKAPLAN ${ }^{1 *}$ iD, Ahmet BALKAYA ${ }^{2}$ iD \\ 1,2Ondokuz Mayıs Üniversitesi Ziraat Fakültesi Bahçe Bitkileri Bölümü, Samsun
}

${ }^{1}$ https://orcid.org/0000-0002-3796-4263; ${ }^{2}$ https://orcid.org/0000-0001-9114-615X

To cite this article:

Özkaplan, M. \& Balkaya, A. (2021). Örtüaltı domates yetiştiriciliğinde değişen sıcaklık ve ışık koşulları ile verim parametreleri arasındaki ilişkinin modellenmesi. Harran Tarım ve Gıda Bilimleri Dergisi, 25(4): 438-447.

DOI: 10.29050/harranziraat.910583

*Address for Correspondence: Melek ÖZKAPLAN

e-mail:

melekozkaplan@omu.edu.tr

Received Date:

06.04.2021

Accepted Date:

18.10.2021

(C) Copyright 2018 by Harran University Faculty of Agriculture. Available on-line www.dergipark.gov.tr/harranziraat

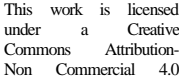
Non Commercial 4.0
Öz

Tarım sektöründe bitkisel üretim planlarının oluşturulmasında, matematiksel modellerin kullanımı yetiştiricilere önemli avantajlar sağlamaktadır. Son yıllarda matematiksel modeller yardımıyla kontrollü koşullar altında yetiştirilen çeşitlerin verim potansiyelinin tahmin edilmesi büyük bir önem kazanmıştır. Örtüaltı sebze yetiştiriciliğinde uygun sıcaklık ve ışıklanma faktörlerinin sağlanması, verim unsurlarını olumlu yönde etkilemektedir. Bu çalışmada, topraksız tarımda domates yetiştiriciliğinde farklı sıcaklık ve ışık koşullarının bazı verim unsurları üzerine olan etkileri modellenmiştir. Araştırma; üç farklı yetiştirme döneminde (2014 yılı ilkbahar, 2014 yılı sonbahar ve 2015 yılı ilkbahar), iki farklı substrat ortamında (Hindistan cevizi lifi ve kayayünü) farklı sıcaklık $\left(16.42,18.14,22.71,24.60,23.96\right.$ ve $26.22{ }^{\circ} \mathrm{C}$ ) ve ışık şiddeti koşullarında $\left(96.10,182.31,223.46,264.54,432.67\right.$ ve $455.93 \mu m o l m^{-2} \mathrm{~s}^{-1}$ ) cam serada yürütülmüştür. Araştırmada, bitki başına en yüksek verim değeri (3.40 kg bitki- ${ }^{1}$ ) ve meyve

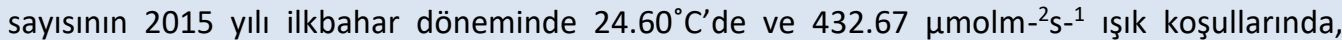
Hindistan cevizi lifi substratında yetiştirilen bitkilerden elde edildiği belirlenmiştir. Hindistan cevizi lifi substratı için bitki başına verim modeli ise; BBV=-6699.96+639.3432xT+5.5225xL$13.6672 \times \mathrm{T}^{2}$ olarak bulunmuştur. Bu çalışmada incelenen verim parametreleri için gerçek ve tahmini değerler arasında istatistiki olarak önemli düzeyde bir ilişkinin olduğu tespit edilmiştir. Bu parametreler için regresyon katsayıları, 0.95-0.99 arasında değişim göstermiştir. Böylece sıcaklık ve ışık yoğunluğunun domatesin verimi üzerindeki etkisi ayrıntılı olarak belirlenmiştir. Bu sonuçlar örtüaltı domates yetiştiriciliği için üretim stratejileri geliştirmek, kaynakların etkin ve verimli kullanılabilesi amacıyla faydalı olacaktır.

Anahtar Kelimeler: Model, Topraksız tarım, Sıcaklık, Işık, Verim

\section{ABSTRACT}

The use of mathematical models in the creation of crop production plans in the agricultural sector offers significant advantages to growers. In recent years, estimating the yield potential of varieties grown under controlled conditions with the help of mathematical has gained great importance. Providing appropriate temperature and lighting factors in greenhouse vegetable cultivation positively affects the yield factors. In this study, the effects of different light and temperature conditions on some yield components in tomato cultivation in soilless agriculture were modelled. The study was conducted in three different growing periods (spring 2014, autumn2014 and spring 2015), on two different substrate media (cocopeat and rockwool), and under different temperatures (16.42, 18.14, 22.71, 24.60, 23.96 and $26.22^{\circ} \mathrm{C}$ ) and light intensity conditions (96.10, 182.31, 223.46, 264.54, 432.67 and $455.93 \mu \mathrm{molm}^{-2} \mathrm{~s}^{-1}$ ) in a glasshouse.In this researchit was determined that the highest yield value $\left(3.40 \mathrm{~kg} \mathrm{plant}^{-1}\right)$ and fruit numbers were obtained from plants grown in cocopeat substrate at $24.60^{\circ} \mathrm{C}$ and 432.67 $\mu \mathrm{molm}-{ }^{2} \mathrm{~s}-{ }^{1}$ light conditions in the spring of 2015. Plant yield model for cocopeat calculated as $B B V=-6699.96+639.3432 \times T+5.5225 x L-13.6672 \times T^{2}$. It has been determined that there is a 
statistically significant relationship between the actual and estimated values for the yield parameters examined in this study. Regression coefficients for the parameters examined varied between 0.95-0.99. Thus, the effect of temperature and light on tomato yield was quantified. These results will be beneficial in order to develop production strategies for greenhouse tomato cultivation and to use the resources effectively and efficiently.

Key Words: Model, Soilless agriculture, Temperature, Light, Yield

\section{Giriş}

Domates insan beslenmesinde yaygın olarak kullanılan, vitamin ve mineral maddeler bakımından zengin olan önemli fonksiyonel sebze türlerinden birisidir. Dünya domates üretimi, 2019 yılı FAO kayıtlarına göre 180766329 tondur (FAO, 2019). Ülkemiz, Dünya toplam domates üretiminde dördüncü sırada yer alan, en önemli domates üreticisi ülkelerden birisidir. 2020 yılı TUik verilerine göre toplam domates üretimimiz 13204015 tona ulaşarak, 2019 yılı TUik verilerine göre (12 841990 ton) \% 2.8 oranında artış göstermiştir. Bu üretimin 4099129 tonu örtüaltı domates üretimine aittir (TUiK, 2020). Ülkemizde örtüaltı sebze yetiştiriciliğinde ilk sırada domates yer almaktadır. Örtüaltında üretilen domatesler, tüketicilere yıl boyunca taze ürün olarak sunulmaktadır. Ülkemizde örtüaltı domates üretim miktarı; kaliteli tohum kullanımı ve modern tarım tekniklerinin yaygınlaşmasına bağlı olarak son yıllarda önemli düzeyde artışlar göstermiştir (Kandemir ve ark., 2016; Tüzel ve ark., 2020).

Son yıllarda artan dünya nüfusu, gıdaya olan talebi büyük ölçüde artırmıştır. Ayrıca tarım alanlarının yerleşim yerlerine açılması ve verimli arazilerin fonksiyonelliğini yitirmesi, araştırıcıları mevcut birim alandan daha yüksek verim artışına yönelik çalışmalara yöneltmiştir. Bu nedenle, yetiştiricilikte yüksek verim ve kaliteli ürün için optimum çevre koşullarının oluşturulması ve modern üretim tekniklerinin kullanılması daha fazla önem kazanmıştır (Savvaş ve ark., 2013; Özkaplan ve Balkaya, 2019; Sagheer ve ark., 2021). Tarım sektöründe son yıllarda üretimde sürdürülebilirliğin sağlanması ve yüksek verim değerlerinin elde edilmesinde, matematiksel modellerin kullanımı da yaygınlaşmaya başlamıştır (Vázquez-Cruz ve ark., 2014; Kandemir ve Uzun 2019; Özkaplan, 2019a; Özkaplan ve Balkaya, 2020). Bu modellerin kullanımı, özellikle modern üretim tekniklerinin kullanıldığı seralarda talep edilen yeni çeşitlerin yetiştiricilik öncesinde planlanması yönünden önemlidir. Bu sayede, yetiştiriciler kendi üretim stratejilerini geliştirebilecektir.

Günümüzde özellikle örtüaltı sebze yetiştiriciliğinde gelişmiş olan ülkelerde, topraksız tarım tekniği yoğun olarak kullanılmaktadır. Ülkemizde ise topraksız tarım sera işletmelerinin sayısı, son yıllarda ticari yetiştiricilikte üstün ürün kalitesi ve yüksek verim eldesi nedeniyle yaygınlaşmaya başlamıştır (Gül, 2018; Özkaplan ve Balkaya, 2019). Topraksız tarım genel olarak, köklendirme ortamı olarak toprak olmadan durgun veya akan besin eriyiklerinde veya besin eriyikleri ile beslenen katı ortamlarda bitkilerin yetiştirilmesi olarak tanımlanmaktadır (Tüzel ve ark., 2019; Özkaplan 2019b). Seracılığın yaygın olduğu bölgelerde katı ortam kültürü, birçok sebze türünün yetiştiriciliğinde daha çok tercih edilmektedir (Güneş ve ark., 2012). Ülkemizde, Hindistan cevizi lifi ve kaya yünü katı ortam kültüründe en çok tercih edilen substratların başında gelmektedir (Toprak ve Gül, 2013; Yarşı ve Çelik, 2019). Birçok araştırıcı, organik bir ortam olan Hindistan cevizi lifinin domateste verim artışı üzerine olumlu etkilerinin olduğunu bildirmişlerdir (Prasad ve ark., 2012; Kılıç, 2014; Reshma ve Sarath 2017; Öztekin ve ark., 2017).

Domates yetiştiriciliğinde verimlilik ve meyve kalite unsurlarını etkileyen en önemli iki çevre faktörü, sıcaklık ve ışıktır. Sıcaklık, bitkide temel fizyolojik yaşam olayları üzerine etkili olan ve üretimi sınırlandıran önemli bir değişkendir (Çeçen ve Çakmakçı 1996; Tüzel ve Gül, 2008). Domateste yetiştiricilik dönemi boyunca sıcaklığın ortalama $20{ }^{\circ} \mathrm{C}$ ile $25^{\circ} \mathrm{C}$ arasında olması istenir. Daha düşük ve yüksek sıcaklıklarda ise verimlilik unsurları belirgin azalışlar gösterir (Uzun, 1996). Bitkiler, fotosentezden solunuma kadar temel 
birçok fizyolojik olayın gerçekleşmesinde ışığa intiyaç duymaktadırlar. Yetiştiricilik periyodu boyunca ışı, domateste önemli rol oynamaktadır. Domateste artan ışık şiddeti ile meyve ağırlığı artmakta ancak artan sıcaklık değerleri ile azalmaktadır. Ayrıca, yüksek sıcaklık ve düşük ışık koşullarında yetiştirilen domates bitkilerinde meyve sayısı değerleri ve diğer verim unsurları da belirgin azalışlar göstermektedir (Uzun, 2000). Bitkinin yetiştirildiği çevre koşullarının (iklimsel parametrelerin) kontrol edilmesiyle bitki büyüme ve gelişiminin bu faktörler ile girdiği etkileşimin sonucunda verim potansiyeli ve ürün kalitesi artmaktadır (Özkaplan, 2019b).

Ülkemizde son yıllarda birçok bitki türünde verim parametrelerini tahmin etmek amacıyla farklı sıcaklık ve ışık şiddetinin etkileri incelenerek birçok matematiksel model geliştirilmiştir (Uzun, 2001; Öner, 2005; Kandemir, 2005; Odabaş ve ark., 2007; Yıldız, 2013). Bu araştırmada, serada topraksız tarım koşullarında domates yetiştiriciliğinde bazı verim unsurları üzerine sıcaklık ve ışığın kantitatif etkilerinin belirlenmesi ve matematiksel model oluşturulması amaçlanmıştır.

\section{Materyal ve Metot}

Bu araştırma, 2014-2015 yıllarında Ondokuz Mayıs Üniversitesi Ziraat Fakültesi Araştırma Uygulama ve Sera Sitesinde bulunan cam serada yürütülmüştür. Bitkisel materyal olarak Bandita $F_{1}$ domates çeşidi kullanılmıştır.

Serada fide dikimleri; 03.04.2014; 29.08.2014 ve 05.03.2015 tarihinde olmak üzere 3 farklı dönemde yapılmıştır. Fide dikimleri, her bir yetiştirme dönemi için \%100 doğal ışık altında ve gölgeleme materyali altında yetiştiricilik olmak üzere iki farklı ekolojik çevrede gerçekleştirilmiştir. Gölgeleme materyali olarak \%55 gölgeleme etkisi, \%45 ışık geçirgenliği olan alüminyum ve polietilen dokumalı gölgeleme ve enerji perdesi kullanılmıştır. Açık sistem topraksız tarım tekniğine uygun niteliklere sahip cam serada, Hindistan cevizi lifi ve kayayünü yetiştirme substratlarında, her bir torbaya 3 adet domates fidesi dikilmiştir. Çalışmada kullanılan besin eriyiği, domates bitkilerinin ihtiyaç duyduğu mineraller ve yetiştirme dönemi dikkate alınarak tarafımızdan Hoagland besin çözeltisi'nden yararlanılarak hazırlanmıştır. Hazırlanan besin çözeltileri, bitkilerin kök bölgesine damlama sulama yöntemi kullanılarak uygulanmıştır. Domates bitkilerinin mineral maddelerden maksimum seviyede faydalanabilmesi için günlük olarak bitki besin çözeltisinde $\mathrm{pH}$ ve EC ölçümleri yapılmıştır. Uygulanan nitrik asit ilavesi ile besin çözeltisi $\mathrm{pH}$ değerinin 6.0-6.5, EC değerinin ise 2.0-2.5 dS m-1 sınırları arasında kalması sağlanmıştır. Denemede, sera içi hava sıcaklık ve fotosentetik aktif radyasyon değerleri, Onset markalı hobo datalogger ve Quantum par sensörleri ile ölçülerek kaydedilmiştir. Günlük olarak kaydedilen bu değerler hesaplanarak yetiştiricilik dönemlerine ait ortalama sıcaklık ve ışık değerleri tespit edilmiştir (Uzun 1996). Çalışmada, üç farklı yetiştirme dönemine ait ortalama sıcaklık ve ışık değerlerine ilişkin veriler Çizelge 1 'de verilmiştir.

Çizelge 1. Yetiştirme dönemlerine ait ortalama sıcaklık ve ışık değerleri

Table 1. Average temperature and light observations for different growing periods

\begin{tabular}{lcccccc}
\hline \multirow{2}{*}{ Ortam } & \multicolumn{2}{c}{$\begin{array}{c}\text { I.Dönem } \\
\text { (2014 yılı ilkbahar) }\end{array}$} & \multicolumn{2}{c}{$\begin{array}{c}\text { II.Dönem } \\
\text { (2014 yılı sonbahar) }\end{array}$} & \multicolumn{2}{c}{$\begin{array}{c}\text { III.Dönem } \\
\text { (2015 yılı ilkbahar) }\end{array}$} \\
\cline { 2 - 7 } & Işık & Gölge & Işık & Gölge & Işık & Gölge \\
\cline { 2 - 7 } & 26.22 & 23.96 & 18.14 & 16.42 & 24.60 & 22.71 \\
Sıcaklık $\left({ }^{\circ} \mathrm{C}\right)$ & 455.93 & 264.54 & 223.46 & 96.10 & 432.67 & 182.31 \\
\hline Işık $\left(\mu \mathrm{molm}^{-2} \mathrm{~s}^{-1}\right)$ & & & & &
\end{tabular}

Her yetiştirme periyodunda, her iki substrat için her bir tekerrürde 4, toplamda 12 domates bitkisinde verim parametreleri incelenmiştir. İncelenen verim unsurları aşağıda verilmiştir.

\section{Ortalama meyve ağırlığı (g)}

Araştırmada tüm uygulamalar için toplam meyve ağırlığının, toplam meyve sayısına bölünmesiyle ortalama meyve ağırlıkları saptanmıştır. 
Bitki başına meyve sayısı (adet bitki ${ }^{-1}$ )

Her uygulama için ayrı ayrı yapılmış olan hasatlar sonucunda bitki başına toplam meyve sayıları adet olarak tespit edilmiştir.

\section{$\operatorname{Verim}\left(\mathrm{kg} \mathrm{bitki}^{-1}\right)$}

Hasat periyodu boyunca her bir uygulama için ayrı ayrı toplanan meyveler tartılmıştır. Araştırmanın sonunda; her bir bitkinin verim değerleri, kümülatif olarak toplanmış ve bitki başına verim değerleri $\mathrm{kg}$ bitki $^{-1}$ olarak hesaplanmıştır.

\section{Verilerin değerlendirilmesi}

Araştırma, faktöriyel deneme desenine göre her uygulamada 3 tekerrür olacak şekilde kurulmuştur. Çoklu regresyon analizleri, Microsoft Office Excel programında yapılmış ve elde edilen modeller, Slide Write Plus paket programında 3 boyutlu grafiklere dönüştürülmüştür.

\section{Araştırma Bulguları ve Tartışma}

\section{Ortalama meyve ağırlığı (OMA)}

Hindistan cevizi lifi ve kayayünü ortamları için, ortalama meyve ağırlığı ile ışık ve sıcaklık değerleri arasındaki ilişkinin regresyon katsayıları sırasıyla $R^{2}$ : 0.97 ve $R^{2}$ : 0.99 olarak bulunmuştur. Domateste ortalama meyve ağırlığı için üretilen matematiksel modeller (1) ve (2)'de verilmiştir.
$\mathrm{OMA}=-78.178+13.5438 \times \mathrm{T}+0.09721 \times \mathrm{L}-0.299 \times \mathrm{T}^{2}$

$\mathrm{SH}=(34.91669) *(3.403535) * *(0.012865) * * *(0.082595) * *$

$\mathrm{OMA}=-31.4871+9.261698 \times \mathrm{T}+0.096094 \mathrm{xL}-0.20736 \times \mathrm{T}^{2}$

$\mathrm{SH}=(12.2296)^{*}(1.192091)^{* * *}(0.004506)^{* * *}(0.028929)^{* * *}$
Model (1)

$\mathrm{R}^{2}=0.97 * * *$

Model (2)

$\mathrm{R}^{2}=0.99 * * *$
Araştırma sonucunda; domateste ortalama meyve ağırlığının artan sıcaklık değeri ile eğrisel olarak arttığı saptanmıştır (Şekil 1). Çalışmada, yüksek ışık şiddeti koşullarında sıcaklığın 24.60 ${ }^{\circ} C^{\prime}$ nin üzerine çıkmasıyla birlikte domateste ortalama meyve ağırığının azaldığı tespit edilmiştir. Bu durumda sıcaklığın optimum değerin üzerine çıkmasıyla; fotosentez ve solunum arasındaki dengenin bozulduğu, mineral madde alımının düştüğü ve böylece bitki büyümesinin yavaşladığı söylenebilir. Optimum değerin üzerindeki sıcaklıklar enzim faaliyetlerini düşürerek metabolik faaliyetleri yavaşlatmaktadır bu nedenle meyvede hücre bölünmesi ve büyümesi azalmaktadır. Birçok araştırmacı, sıcaklığın optimum değerin üzerine çıkmasıyla domateste meyve ağırlığının azaldığını ortaya koymuştur (Seligman, 1990; Uzun 2001). Şekil 1 incelendiğinde domateste hem Hindistan cevizi lifi hem de kayayünü substratlarında ortalama meyve ağırlığının artan ışık şiddeti (ışığın $96.10 \mu \mathrm{molm}^{-2}{ }^{2}$ 1 den $455.93 \mathrm{\mu molm}^{-2} \mathrm{~s}^{-1}$ ye artmasıyla) ile doğrusal olarak artış gösterdiği saptanmıştır. Artan ışık şiddetinin etkisiyle yapraklarda klorofil oluşumu ve fotosentetik reaksiyonlar artmakta, bu sayede bitkilerde yüksek oranda organik madde üretilerek dokuların iyi bir şekilde olgunlaşması temin edilmektedir (Uzun 1996; Eriş 2007). Artan ışık şiddetinin etkisiyle yapraklarda fotosentetik reaksiyonlar artmakta, bu sayede bitkilerde yüksek oranda organik madde üretilmektedir (Uzun 1996). De Koning, (1994) domates yetiştiriciliğinde artan ışık şiddeti ile ortalama meyve ağırlığının artış gösterdiğini bildirirken; Wada ve ark. (2006) azalan ışık şiddetin domateste ortalama meyve ağırlığının azaldığını bildirmişlerdir. Uzun (2000) ve Uzun (2001) yaptığı çalışmalarında artan ışık şiddeti değerlerinin domateste meyve ağırlığını arttırırken, artan sıcaklık değerlerinin optimumun üzerine çıkmasıyla birlikte yapraklarda fotosentetik aktiviteyi düşürdüğünden, ortalama meyve ağırlığının azaldığını bildirmiştir. 
(a)

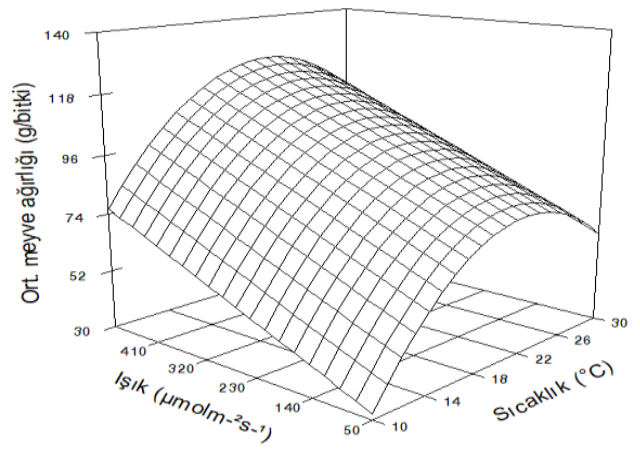

(b)

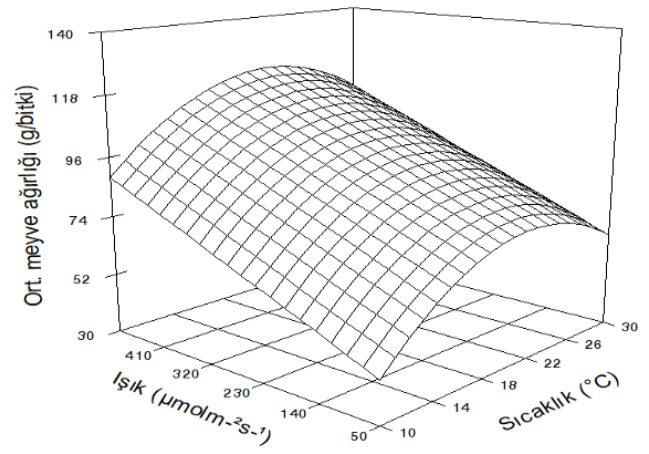

Şekil 1. Hindistan cevizi lifi (a) ve kayayünü (b) substratlarında yetiş̧irilen domateste, sıcaklık $\left({ }^{\circ} \mathrm{C}\right)$ ve ışık şiddetine $\left(\mu \mathrm{molm} \mathrm{m}^{-2} \mathrm{~s}^{-1}\right)$ bağlı olarak ortalama meyve ağırlığı değerlerinin $\left(g\right.$ meyve $\left.^{-1}\right)$ değişimi

Figüre 1. Variation of average fruit weight values per plant $\left(g\right.$ fruit $\left.{ }^{-1}\right)$ depending on temperature $\left({ }^{\circ} \mathrm{C}\right)$ and light intensity $\left(\mu \mathrm{molm} \mathrm{m}^{-2} \mathrm{~s}^{-1}\right)$ in tomatoes grown on cocopeat (a) and rockwool (b) substrates

Çalışmada ortalama meyve ağırlığı bakımından, substratlar arasında istatistiksel olarak önemli düzeyde farklılıklar olduğu görülmüştür (Çizelge 2). Hindistan cevizi lifi yetiştirme ortamında yetiştirilen domateslerde, ortalama meyve ağırlığının (99.5 g), kayayünü yetiştirme ortamına (97.4 g) göre daha fazla olduğu belirlenmiştir. Bu çalışmada ortalama meyve ağırlığı değerleri üzerine dikim dönemlerinin etkileri karşılaştırıldığında; ilkbahar yetiştiriciliğinin sonbahar yetiştiriciliğine göre öne çıktığı saptanmıştır $(\mathrm{P}<0.05)$.Otalama meyve ağırlığı değerleri 70.8 g-116.7 g arasında değişim göstermiştir. Çalışmada artan sıcaklık ve ışık değerlerinin ortalama meyve ağırlığı üzerinde olumlu yönde etkileri olduğu saptanmıştır.

Dannehl ve ark., (2015) kayayünü büyüme ortamında yetiştirdikleri domates bitkilerinde, ortalama meyve ağırlığının 89.4 g olduğunu tespit etmişlerdir. Dönmez, (2015) Hindistan cevizi lifi ve kayayünü sustalarında ortalama meyve ağırlığının sırasıyla 91.9 g ve 86.5 g olduğunu bildirmiştir. Araştırma bulguları belirtilen literatürlerle benzerlik göstermiştir.

Çizelge 2. Dikim dönemlerine göre farklı büyüme ortamlarında yetiştirilen domateslerde ortalama meyve ağırlı̆̆ı (g) değerleri $(\mathrm{P}<0.05)$

Table 2. Average fruit weight $(g)$ values of tomatoes grown in different growing media according to planting periods $(P<0.05)$

\begin{tabular}{|c|c|c|c|c|c|c|c|c|c|c|}
\hline \multicolumn{11}{|c|}{ Ortalama Meyve Ağırlığı (g meyve ${ }^{-1}$ ) } \\
\hline \multirow{2}{*}{ Ortam } & \multicolumn{3}{|c|}{ I.Dönem } & \multicolumn{3}{|c|}{ II.Dönem } & \multicolumn{3}{|c|}{ III.Dönem } & \multirow[b]{2}{*}{ Ortam* } \\
\hline & Işık* & Gölge* & Ort. ${ }^{*}$ & Işı** & Gölge* & Ort.* & Işık* & Gölge* & Ort. ${ }^{*}$ & \\
\hline $\mathrm{HCL}$ & $116.7 a$ & $101.6 c$ & $109.2 a$ & $93.7 e$ & $70.8 \mathrm{~h}$ & $82.3 d$ & $113.1 b$ & $100.7 \mathrm{c}$ & $106.9 b$ & $99.5 a$ \\
\hline KY & $112.7 \mathrm{~b}$ & $97.3 d$ & $105.5 \mathrm{c}$ & $90.7 f$ & $73.5 \mathrm{~g}$ & $81.9 d$ & $112.1 b$ & $98.4 d$ & $105.2 c$ & $97.4 b$ \\
\hline Ort.* & $114.7 a$ & $99,4 c$ & & $92.1 d$ & $72.0 \mathrm{e}$ & & $112.5 b$ & $99.6 c$ & & \\
\hline
\end{tabular}

Dönem* 107.2a $106.1 \mathrm{a}$

HCL: Hindistan cevizi lifi; KY (Kayayünü)

\section{Bitki başına meyve sayısı (BBMS)}

Çalışmada bitki başına meyve sayısının tahmin edilebilmesi için üretilen matematiksel modellerde Hindistan cevizi lifi (3) ve kayayünü (4) substratları için hesaplanan regresyon katsayıları sırasıyla $R^{2}$ : 0.95 ve $R^{2}$ : 0.96 olarak önemli düzeyde olduğu bulunmuştur.
BBMS $=-70.8743+7.321874 x T+0.035685 x L-0.16008 \times T^{2}$

$\mathrm{SH}=(19.32079) * *(1.883311)^{* *}(0.007119) * *(0.045703) * *$

BBMS $=-66.0634+6.787456 x T+0.033611 x L-0.15102 \times T^{2}$

$\mathrm{SH}=(13.88761)^{* *}(1.353707)^{* *}(0.005117)^{* *}(0.032851)^{* *}$
Model (3)

$\mathrm{R}^{2}=0.95^{* * *}$

Model (4)

$\mathrm{R}^{2}=0.96 * * *$ 
Farklı ışık ve sıcaklık değerlerinin bitki başına meyve sayısı üzerine etkileri, Şekil 2'de verilmiştir. Çalışmada, artan sıcaklık değerinin bitki başına meyve sayısını artırdığı belirlenmiştir. Domateste ortalama meyve sayısının, hem yüksek hem de düşük sıcaklık koşullarında artan ışık şiddetinin etkisiyle birlikte doğrusal olarak artış gösterdiği belirlenmiştir. Ortamlar arasında, bitki başına meyve sayısı bakımından değişen ışık şiddetinin etkisi ile birlikte optimum sıcaklık değerlerinin farklılık gösterdiği ve artan ışık şiddetinin etkisiyle optimum sıcaklık değerinin azalış gösterdiği saptanmıştır (Şekil 2).

(a)

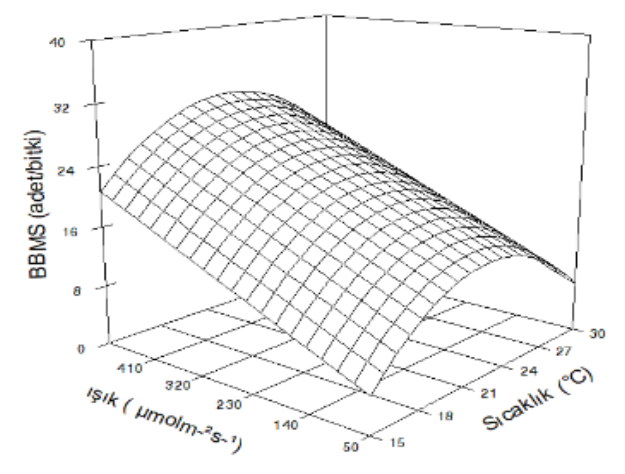

Dorais ve ark., (1991), domateste yüksek ışık şiddetinin bitkilerin meyve sayısı üzerine olan etkilerinin, düşük ışık şiddetine oranla bitki başına \%10'luk bir artış sağladığını belirtmişlerdir. Uzun (1996) ve Sevgican (1999), domateste meyve sayısının artan ışık şiddeti ile birlikte artış gösterdiğini bildirmişlerdir. Uzun (2000), domates yetiştiriciliğinde düşük ışık ve yüksek sıcaklık koşullarında meyve sayısının azaldığını bildirmiştir. Dueck ve ark., (2012), domateste artan ışık şiddeti ile bitki başına meyve sayısının artış gösterdiğini bildirmişlerdir. (b)

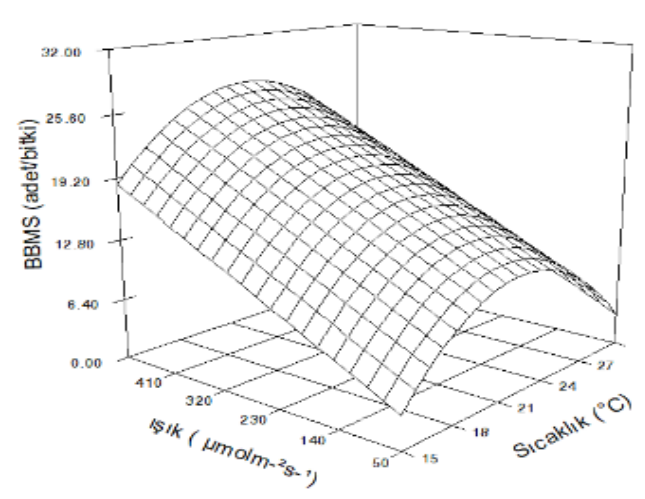

Şekil 2. Hindistan cevizi lifi (a) ve kayayünü substratlarında yetiştirilen domateste, sıcaklık $\left({ }^{\circ} \mathrm{C}\right)$ ve ışık şiddetine $\left(\mu \mathrm{molm}{ }^{-2} \mathrm{~s}^{-1}\right)$ bağlı olarak bitki başına meyve sayısı değerlerinin (adet bitki- ${ }^{1}$ ) değişimi

Figure 2. The variation in the number of fruits per plant (adet bitki $\left.i^{-1}\right)$ depending on temperature $\left({ }^{\circ} \mathrm{C}\right.$ ) and light intensity $\left(\mu \mathrm{molm} \mathrm{s}^{-2} \mathrm{~s}^{-1}\right)$ in tomatoes grown on cocopeat (a) and rockwool (b) substrates

İki farklı substrat ortamında yetiştirilen sayısı değerlerinin istatistiksel olarak önemli domates bitkilerin ortalama bitki başına meyve düzeyde olduğu belirlenmiştir (Çizelge 3).

Çizelge 3. Dikim dönemlerine göre farklı substrat ortamlarında yetiştirilen domateslerde toplam meyve sayısı değerlerinin değişimi $(P<0.05)$

Table 3. Variationof the total number of fruit values in tomatoes grown in different substrate media according to planting period $(P<0.05)$

\begin{tabular}{|c|c|c|c|c|c|c|c|c|c|c|}
\hline \multicolumn{11}{|c|}{ Bitki Başına Meyve Sayısı } \\
\hline \multirow{2}{*}{ Ortam } & \multicolumn{4}{|c|}{ I.Dönem } & \multicolumn{2}{|c|}{ II.Dönem } & \multicolumn{4}{|c|}{ III.Dönem } \\
\hline & Işı|k* & Gölge* & Ort.* & Işı** & Gölge* & Ort.* & Işı** & Gölge* & Ort.* & Ortam* \\
\hline $\mathrm{HCL}$ & $26.0 \mathrm{~b}$ & $22.0 c$ & $24.00 \mathrm{~b}$ & $15.66 f$ & $10.66 \mathrm{~h}$ & $13.16 \mathrm{e}$ & $30.0 a$ & $22.66 c$ & $26.33 a$ & 21.16a \\
\hline KY & $22.66 c$ & 18.33 e & $20.50 d$ & $13.66 \mathrm{~g}$ & 8.661 & $11.16 f$ & $25.33 b$ & $20.0 d$ & $22.66 c$ & $18.11 b$ \\
\hline Ort.* & $24.33 b$ & $20.16 d$ & & $14.66 \mathrm{e}$ & $9.66 f$ & & $27.66 a$ & $21.33 c$ & & \\
\hline
\end{tabular}

\begin{tabular}{llll}
\hline Dönem* $22.50 \mathrm{~b}$ & $12.16 \mathrm{c}$ & $24.50 \mathrm{a}$ \\
\hline
\end{tabular}

HCL: Hindistan cevizi lifi; KY (kayayünü)

Araştırmada, en yüksek meyve sayısı değeri; ortalama 27.66 adet ile $24.60^{\circ} \mathrm{C}$ sıcaklık ve 432.67 $\mu \mathrm{molm}-{ }^{2} \mathrm{~s}^{1}$ Işık değerlerinde belirlenmiştir.
Hindistan cevizi lifinde (21.16 adet), kayayünü yetiştirme ortamına göre (18.11 adet) bitki başına ortalama meyve sayısının daha fazla olduğu 
bulunmuştur (Çizelge 3). Araştırma sonucunda, Hindistan cevizi lifi substratı kullanımının bitkide meyve sayısını arttırıcı rol oynadığı ve meyve sayısının \%14-15 oranında arttırdığı saptanmıştır. $\mathrm{Bu}$ artışın nedeninin, su tutma kapasiesi ve organik madde içeriği yüksek olan Hindistan cevizi lifinin, yetiştiricilikteki pozitif etkilerinden kaynaklandığı söylenebilir. Kılıç, (2014) sonbahar yetiştiricilik periyodunda domateste bitki başına meyve sayısının Hindistan cevizi lifi ortamında ortalama 13 adet, kayayünü yetiştirme ortamında ise 15 adet olduğunu bildirmiştir. Araştırma bulguları daha önce yürütülen yukarıdaki çalışmaları desteklemektedir.

\section{Bitki başına verim (BBV)}

Domateste bitki başına verim ile sıcaklık ve ışık şiddeti arasındaki ilişkinin derecesi $\left(R^{2}\right)$ regresyon analizi sonucunda Hindistan cevizi lifi substratları için $R^{2}$ : 0.97; kayayünü substratları için ise yine $R^{2}$ : 0.97 gibi oldukça önemli bir ilişki olduğu saptanmıştır ve eşitliği sırasıyla Model (5) ve (6)'da verilmiştir.

$$
\begin{aligned}
& \mathrm{BBV}=-6699.96+639.3432 \times \mathrm{T}+5.5225 \times \mathrm{L}-13.6672 \times \mathrm{T}^{2} \\
& \mathrm{SH}=(2164.286)^{* *}(210.9656)^{* *}(0.797447)^{* * *}(5.119613)^{*} \\
& \mathrm{BBV}=-5686.07+547.7298 \times \mathrm{T}+5.051563 \times \mathrm{L}-12.0947 \times \mathrm{T}^{2} \\
& \mathrm{SH}=(1808.373)^{* *}(176.2728)^{* *}(0.666308)^{* * *}(4.277703)^{*}
\end{aligned}
$$

Model (5)

$\mathrm{R}^{2}=0.97^{* * *}$

Model (6)

$\mathrm{R}^{2}=0.97 * * *$
Domates bitkilerinde $16.42{ }^{\circ} \mathrm{C}$ ile $26.22{ }^{\circ} \mathrm{C}$ aralığındaki tüm sıcaklık değerlerinde, ışık şiddetinin $96.10 \mu \mathrm{molm}^{-2} \mathrm{~s}^{-1}$ den $455.93 \mu \mathrm{molm}^{-2} \mathrm{~s}-$ 1 ye artmasıyla, bitki başına verim değerinin doğrusal olarak artış gösterdiği görülmüştür (Şekil 3). Çalışmada, artan ışık şiddeti klorofil pigmentlerinin etisiyle, ışık absorbsiyonunu arttırmış böylece fotosentez ile üretilen organik madde miktarının domates verimi üzerine olumlu etkileri söz konusu olmuştur. Bitki başına verim değerinin artan sıcaklık şiddeti ile belirli bir optimum sıcaklığa $\left(24.60{ }^{\circ} \mathrm{C}\right)$ kadar arttığı, bu sınırın üzerindeki sıcaklık koşullarında ise

(a)

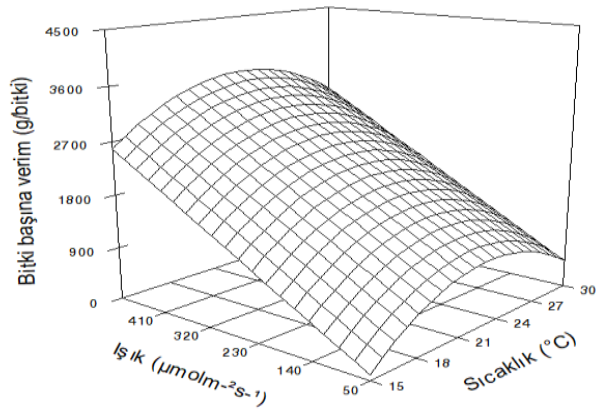

azalmaya başladığı tespit edilmiştir. Birçok araştırıcı tarafından bu sonuçlar ile benzer sonuçlar ortaya konulmuştur (Dorais ve ark., 1991; Uzun, 2000).

Araştırma sonucunda elde edilen verim değerleri istatistiksel olarak analize tabi tutulduğunda, uygulamalar arasında çok önemli $(P<0.05) \quad$ düzeyde farklılıkların olduğu belirlenmiştir (Çizelge 4). Araştırmada en yüksek bitki başına verim değeri, ortalama $3.40 \mathrm{~kg}$ ile yüksek ışık (432.67 $\mu \mathrm{molm}^{-2} \mathrm{~s}^{-1}$ ) yüksek sıcaklık $\left(24.60{ }^{\circ} \mathrm{C}\right)$ koşullarında Hindistan cevizi lifi substratlarında saptanmıştır.

(b)

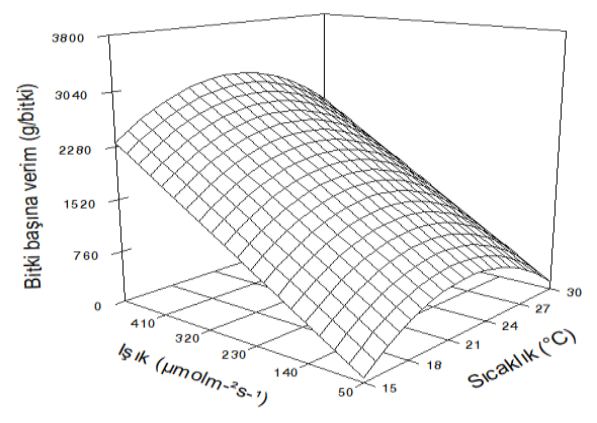

Şekil 3. Hindistan cevizi lifi (a) ve kayayünü (b) substratlarında yetiştirilen domateste, sıcaklık $\left({ }^{\circ} \mathrm{C}\right)$ ve ışık şiddetine $\left(\mu \mathrm{molm} \mathrm{m}^{-2} \mathrm{~s}^{-1}\right)$ bağlı olarak bitki başına verim değerlerinin $\left(\mathrm{g} \mathrm{bitki}^{-1}\right)$ değişimi

Figure 3. Variation in yield per plant $\left(\mathrm{g}\right.$ bitki- $\left.{ }^{-1}\right)$ depending on temperature $\left({ }^{\circ} \mathrm{C}\right)$ and light intensity $\left(\mu \mathrm{molm} \mathrm{m}^{-2} \mathrm{~s}^{-1}\right)$ in tomatoes grown on cocopeat (a) and rockwool (b) substrates 
Çizelge 4. Dikim dönemlerine göre farklı büyüme ortamlarında yetiştirileen domateslerde bitki başına verim (kg) değerleri (* $\mathrm{P}<0.05)$

Table 4. Yield ( $\left.\mathrm{kg} \mathrm{bitki}^{-1}\right)$ values per plant for tomatoes grown in different growth environments according to planting periods $(* P<0.05)$

\begin{tabular}{|c|c|c|c|c|c|c|c|c|c|c|}
\hline \multicolumn{11}{|c|}{ Bitki Başına Verim (kg bitki ${ }^{-1}$ ) } \\
\hline \multirow{2}{*}{ Ortam } & \multicolumn{3}{|c|}{ I.Dönem } & \multicolumn{3}{|c|}{ II.Dönem } & \multicolumn{3}{|c|}{ III.Dönem } & \multirow[b]{2}{*}{ Ortam* } \\
\hline & Işık* & Gölge* & Ort.* & Işık* & Gölge* & Ort.* & Işık* & Gölge* & Ort.* & \\
\hline $\mathrm{HCL}$ & $3.03 b$ & $2.23 e$ & $2.63 b$ & $1.46 \mathrm{~h}$ & $0.75 j$ & $1.11 \mathrm{e}$ & $3.40 a$ & $2.28 \mathrm{e}$ & $2.84 a$ & $2.19 a$ \\
\hline KY & $2.55 d$ & $1.78 \mathrm{~g}$ & $2.17 d$ & $1.23 ı$ & $0.63 k$ & $9.36 f$ & $2.83 c$ & $1.96 f$ & $2.40 c$ & $1.83 b$ \\
\hline Ort.* & $2.79 b$ & $2.01 d$ & & $1.35 \mathrm{e}$ & $0.69 f$ & & $3.12 \mathrm{a}$ & $2.12 \mathrm{c}$ & & \\
\hline Dönem* & & $2.40 \mathrm{~b}$ & & & $1.02 c$ & & & $2.62 \mathrm{a}$ & & \\
\hline
\end{tabular}

HCL: Hindistan cevizi lifi; KY (kayayünü)

Düşük ışık şiddeti koşullarındaki yüksek sıcaklık değerleri bitkide vejetatif devre ile generatif devre arasındaki ilişkinin bozulmasına neden olmaktadır. Bitki bu koşullar altında vejetatif büyüme eğilimi gösterdiğinden verim değerlerinde bir azalma söz konusu olduğu düşünülmektedir.

Çalışmada, 2014 yılı ilkbahar dönemi yüksek sıcaklık ve yüksek ışık şiddetinin etkisiyle, 2015 yılı ilkbahar dönemine göre erkencilik sağlanmıştır. Bunun yanında, 2015 yılı ilkbahar döneminde domates bitkilerinin, yavaş ancak daha kararlı bir büyüme göstererek bitki verimini artırdığı tespit edilmiştir. Benzer bir şekilde, Bozköylü ve Daşgan (2010) topraksız tarım yöntemiyle ilkbahar döneminde yetiştirdikleri domateste bitki başına verim değerlerinin, $1.49 \mathrm{~kg}-3.35 \mathrm{~kg}$ aralığında değişim gösterdiğini bildirmişlerdir. Kılıç, (2014) domateste örtüaltı yetiştirme substratlarını değerlendirdiği bir araştırmada, bir üretim sezonu boyunca en yüksek bitki başına verim değerinin Hindistan cevizi lifi substratlarında $5.06 \mathrm{~kg}$ ve kayayünü substratlarında $4.09 \mathrm{~kg}$ olduğunu bildirmiştir. Yine Dönmez, (2015) domateste yaptığı çalışmada, en yüksek bitki başına verim değerinin $3.07 \mathrm{~kg} \mathrm{bitki-1}^{-1}$ ile Hindistan cevizi lifi substrat ortamında olduğunu, bunu $2.43 \mathrm{~kg} \mathrm{bitki-1}^{-1}$ ile kayayünü büyüme ortamının takip ettiğini bildirmiştir. Elde ettiğimiz çalışma sonuçları bu çalışma sonuçlarıyla benzerlik göstermiştir. Her iki çalışmada da Hindistan cevizi lifi substratlarının verim değerleri bakımından öne çıktığı tespit edilmiştir.

\section{Sonuçlar}

Domates yetiştiriciliğinde verim değerleri genetik yapıya ve değişen çevre koşullarına göre belirgin farklılıklar göstermektedir. Bu nedenle, verim parametreleri bakımından değişen çevre koşullarına göre optimum şartların oluşturulması oldukça önemlidir. Tarımsal üretimde verim unsurlarını azaltan dış etkenler, örtüaltı yetiştiriciliğinde etkin olarak kontrol altına alınabilmekte böylece ürünün performansında artışlar sağlanabilmektedir. Bu amaçla, iklimsel parametreler ile yetiştirilecek bitki türü arasındaki interaksiyonun belirlenmesi bitki fizyologlarının uzun yıllardır üzerinde çalıştıkları, süre gelen zaman içerisinde güncelliğini koruyan önemli konulardan birisi olmuştur. Bu araştırmada, salkım domateste bazı verim unsurları üzerine farklı sıcaklık $\left(16-26^{\circ} \mathrm{C}\right)$ ve ışık (96.1-455.93 $\mu$ molm $\left.^{-2} \mathrm{~s}^{-1}\right)$ değerlerinin kantitatif etkileri ayrıntılı olarak belirlenmiştir. Işık ve sıcaklık domateste meyve ağırlığı, meyve sayısı ve verimliliği büyük ölçüde etkilemektedir. Çalışmada incelenen parametreler için optimum sıcaklık koşulları tespit edilmiş ve bu değerin üzerindeki sıcaklıklarda azalışlar sözkonusu olmuştur. Artan ışık yoğunluğunun ise domateste meyve ağırlığı, meyve sayısı ve verim değerlerini artırdığı belirlenmiştir. Bitki başına en yüksek verim değerine (3.4 bitki $\left.\mathrm{kg}^{-1}\right)$, Hindistan cevizi lifi substratında, optimum $432.67 \mu^{m o l} \mathrm{~m}^{-2} \mathrm{~s}^{-1}$ (yüksek ışık şiddeti koşullarında) ışık ve $24.60{ }^{\circ} \mathrm{C}$ sıcaklık koşullarında ulaşılmıştır. Böylece, ülkemiz iklim koşullarına uygun topraksız tarım domates yetiştiriciliği için kullanılabilecek verim modelleri 
oluşturulmuştur. $\mathrm{Bu}$ modellerin üreticiler ve araştırıcılar tarafından domates üretimi planlamasında kullanımı tarımda sürdürülebilirlik ve etkin kaynak kullanımı yönünden ülke ekonomisine büyük katkılar sağlayacaktır.

\section{Ekler}

$\mathrm{Bu}$ çalışma birinci yazarın doktora tezi olan ve aynı zamanda Ondokuz Mayıs Üniversitesi Bilimsel Araştırma Fonu tarafından desteklenen PYO.ZRT.1904.13.024 numaralı projesinden türetilmiştir.

Çıkar Çatışması Beyanı: Makale yazarları arasında herhangi bir çıkar çatışması olmadığını beyan ederler.

Yazar Katkısı: Prof. Dr. Ahmet Balkaya denemeyi tasarlamış, Melek Özkaplan denemeyi kurmuş, Prof. Dr. Ahmet Balkaya ve Melek Özkaplan denemeyi yürütmüş, Melek Özkaplan analizleri yapmış, Prof. Dr. Ahmet Balkaya verileri incelemiş, Melek Özkaplan literatür taraması yapmış, Prof. Dr. Ahmet Balkaya ve Melek Özkaplan makaleyi birlikte yazmışlardır.

\section{Kaynaklar}

Bozköylü, A., \& Daşgan, H. (2010). Sera topraksız domates yetiştiriciliğinde kimyasal ve organik gübrelemenin karşılaştırılması. TÜBAV Bilim Dergisi, 3(2), 174-181.

Çeçen, S. \& Çakmakçı, S. (1996). Yüksek sıcaklığın bitkilerin gelişimi üzerine etkileri. Akdeniz Üniversitesi Ziraat Fakültesi Dergisi, 9 (1) , 216-231.

Gül, A. (2018). Soilless cultivation in Turkey. $X X X$. International Horticultural Congress, 12-16 Ağustos, İstanbul, Turkey. http://www.ihc2018. org/files/downloads/Vol57-N03-2.pdf

Güneş, A., İnal, A., Karaman, M. R. \& Geboloğlu, N. (2012). Topraksız yetiştiricilik sisteminde bitki besleme yöntemi, Gübretaş Rehber Kitaplar Dizisi: 2.

Dannehl, D., Suhl, J., Ulrichs, C., \& Schmidt, U. (2015). Evaluation of substitutes for rock wool as growing substrate for hydroponic tomato production. Journal of Applied Botany and Food Quality, 88(1).

De Koning, A. N. M. (1994). Development and dry matter distribution in glasshouse tomato: a quantitative approach. (Yayımlanmamış doktora tezi) Wageningen Agricultural University, Wageningen.

Dorais, M., Andre, G. \& Trudel M. J. (1991). Annual greenhouse tomato production under a sequential intercropping system using supplemental light.
Scientia Horticulturae, (45). 225-234.

Dueck, T. A., Janse, J., Li, T., Kempkes, F.L.K. \& Eveleens Clark, B. A. (2012). Influence of diffuse glass on the growth and production of tomato. Acta Horticulturae (956). 75-82.

Dönmez, i. (2015). Bazı bölgesel organik atıkların topraksız tarımda (torba kültürü) kullanılabilme imkanlarının belirlenmesi. (Yayımlanmamış yüksek lisans tezi) Ondokuz Mayıs Üniversitesi Fen Bilimleri Enstitüsü, Samsun.

Eriş, A. (2007). Bahçe Bitkileri Fizyolojisi. Uludağ Üniversitesi Ziraat Fakültesi Yayınları Ders Kitabı: 152. Bursa.

FAO, (2019). Statistical data of FAO. Retrieved from: http://www.fao.org/faostat/en/\#data/QC

Kandemir, D. (2005). Sera şartlarında sıcaklık ve ışığın biberde (Capsicum annuum L.) büyüme, gelişme ve verim üzerine kantitatif etkileri (Yayımlanmamış doktora tezi). Ondokuz Mayıs Üniversitesi Fen Bilimleri Enstitüsü, Samsun.

Kandemir, D., Kurtar, E. S. \& Demirsoy, M. (2016). Türkiye örtüaltı domates yetiştiriciliğindeki gelişmeler. Türkiye Tohumcular Birliği Dergisi, 5(17), 22-27.

Kandemir, D. \& Uzun, S. (2019). Farklı ışık ve sıcaklık şartlarının sera biber yetiştiriciliğinde büyüme parametreleri üzerine kantitatif etkilerinin modellenmesi. Anadolu Tarım Bilimleri Dergisi, 34 (1), 1-11. DOI: 10.7161/omuanajas.473656

Kılıç, P. (2014). Topraksız domates yetiştiriciliğinde kullanılan farklı ortamların verim, kalite ve bitki besin elementi tüketimi üzerine etkileri (Yayımlanmamış yüksek lisans tezi). Süleyman Demirel Üniversitesi Fen Bilimleri Enstitüsü, Isparta.

Odabaş, M., Gülümser, A. \& Uzun, S. (2007). The quantitative effects of temperature and light on growth, development and yield of faba bean (Vicia faba L.). I. growth. International Journal of Agricultural Research, 2(9): 765-775

Öner, F. (2005). Işık ve sıcaklığın mısırda (Zea mays L.) büyüme, gelişme ve verime kantitatif etkileri (Yayımlanmamış yüksek lisans tezi). Ondokuz Mayıs Üniversitesi Fen Bilimleri Enstitüsü, Samsun.

Özkaplan, M. (2019a). Tarımda matematiksel model kullanımı. 3. Uluslararası Unidokap Karadeniz Sempozyumu, (ss. 456-461), 21-23 Haziran, Tokat, Türkiye.

Özkaplan, M. (2019b). Çevreci ve sürdürülebilir üretim tekniği: Hidroponik. 3. Uluslararası Unidokap Karadeniz Sempozyumu, (ss. 445-448), 21-23 Haziran, Tokat, Türkiye.

Özkaplan, M. \& Balkaya, A. (2019). Işık ve sıcaklığın topraksız tarım koşullarında salkım domatesin meyve kalitesine etkisi. Anadolu Tarım Bilimleri Dergisi, 34 (3) , 227-238. DOI: 10.7161/omuanajas.551680

Özkaplan, M. \& Balkaya, A. (2020). Topraksız tarımda domates yetiştiriciliğinde bitki gelişme parametreleri ile sıcaklık ve ışık arasındaki ilişkilerin modellenmesi. Mediterranean Agricultural Sciences, 33 (2), 181-187.

Öztekin, G. B., Tüzel, Y. \& Tüzel, i. H. (2017). Serada topraksız domates yetiştiriciliğinde silisyumun tuz stresine etkisi. Akademik Ziraat Dergisi, 6, 243-256.

Prasad, L.B., Babu Adhikari, P., Soo Yoon, C. \& Hee Kang W. (2012). Yield and fruit quality of tomato (Lycopersicon esculentum Mill.) cultivars established 
at different plantingbed size and growing substrates. Horticulture, Environment and Biotechnology, 53, 102-107.

Reshma, T. \& Sarath, P. S. (2017). Standardization of growing media for the hydroponic cultivation of tomato. International Journal of Current Microbiology and Applied Sciences, 6(7), 626-631.

Sagheer, A., Mohammed, M., Riad, K. \& Alhajhoj, M. (2021). A cloud-based tot platform for precision control of soilless greenhouse cultivation. Sensors, 21(1), 223.

Savvas, D., Gianquinto, G., Tuzel, Y. \& Gruda, N. (2013). 12. Soilless culture. Good Agricultural Practices for greenhouse vegetable crops, 303.

Sevgican, A. (1999). Örtüaltı Sebzeciliği. Cilt I Ege Üniversitesi. Ziraat Fakültesi Yayınları No: 528.

Seligman, N. G. (1990). The crop model record: promise or poor show?. In Theoretical production ecology: Reflections and prospects, (pp. 249-263).

Toprak, E. \& Gül A. (2013). Topraksız tarımda kullanılan ortam domates verimi ve kalitesini etkiliyor mu? Tarım Bilimleri Araştırma Dergisi, 6 (2), 41-47.

TUiK, (2020). Türkiye istatistik kurumu. https://data.tuik.gov.tr/Bulten/Index?p=BitkiselUretim-Istatistikleri-2020-33737

Tüzel, Y. \& Gül, A. (2008). Seralarda iyi tarım uygulamaları. Bahçe Ürünlerinde Çevre Dostu Uygulamaların Yaygınlaştırılması ve İş Olanağı Yaratılması için Ziraat Mühendislerinin Kapasitelerinin Geliştirilmesine Yönelik Eğitim Projesi. Proje No: TR0205.01/002/02/011, İzmir.

Tüzel, Y., Gül, A., Tüzel, I. H. \& Öztekin, G. B. (2019). Different soilless culture systems and their management. Journal of Agricultural, Food Environmental Sciences. 73, 7-12.
Tüzel, Y., Gül, A., Öztekin, G. B., Engindeniz, S., Boyacı, F., Duyar, H. \& Cebeci, E. (2020). Türkiye'de örtüaltı yetiştiriciliği ve yeni gelişmeler. Türkiye Ziraat Mühendisliği IX. Teknik Kongresi, 725-750.

Uzun, S. (1996). The quantitative effects of temperature and light environment on the growth, development and yield of tomato and aubergine (Unpublished PhD thesis). The University of Reading, England.

Uzun, S. (2000). Sıcaklık ve ışığın bitki büyüme, gelişme ve verimine etkisi (III. Verim). Ondokuz Mayıs Üniversitesi Ziraat Fakültesi Dergisi, 15 (1), 105-108.

Uzun, S. (2001). Serada domates ve patlıcan yetiştiriciliğinde bazı büyüme ve verim parametreleri ile sıcaklık ve ışık arasındaki ilişkiler. 6. Ulusal Seracılık Sempozyumu, (pp. 97-102) 5-7 Eylül, Türkiye (Muğla).

Vázquez-Cruz, M. A., Espinosa-Calderón, A., JiménezSánchez, A. R. \& Guzmán-Cruz, R. (2014). Mathematical modeling of biosystems. Springer, Cham. In Biosystems Engineering: Biofactories for Food Production in the Century XXI, 51-76.

Wada T., Ikeda H., Matsushita K., Kambara A., Hirai H. \& Abe K. (2006). Effect of shading in summer on yield and quality of tomatoes grown on a single-truss system. Journal Japanese Society for Horticultural Science. 7551-58. 10.2503/jjshs.75.51

Yarşı, G. \& Çelik, Y. (2019) Silifke'de topraksız tarım. Erasmus Fen, Mühendislik ve Mimarlık Bilimlerinde Uluslararası Akademik Çalışmalar Sempozyumu. (ss. 5-11). 5-6 Nisan, İzmir, Türkiye.

Yıldız, D. (2013). Gölgelemenin sırık domates yetiştiriciliğinde verim, kalite ve bazı agronomik özellikler üzerine etkisi. (Yayımlanmamış yüksek lisans tezi). Gaziosmanpaşa Üniversitesi Fen Bilimleri Enstitüsü, Tokat. 